\title{
Effect of basalt, silica sand and fly ash on the mechanical properties of quaternary polymer concretes
}

\author{
M HASSANI NIAKI ${ }^{1}$, A FEREIDOON ${ }^{1}$ and M GHORBANZADEH AHANGARI ${ }^{2, *}$ \\ ${ }^{1}$ Department of Mechanical Engineering, Semnan University, 35131-19111 Semnan, Iran \\ ${ }^{2}$ Department of Mechanical Engineering, Faculty of Engineering and Technology, University of Mazandaran, \\ 57416-13534 Babolsar, Iran \\ *Author for correspondence (ghorbanzadeh.morteza@gmail.com; m.ghorbanzadeh@umz.ac.ir)
}

MS received 18 March 2017; accepted 20 September 2017; published online 17 May 2018

\begin{abstract}
The aim of this study is to manufacture quaternary polymer concretes (PCs) and optimize the weight percentages of the epoxy resin, ultrafine fly ash, silica sand and basalt aggregates. For this, we first manufactured binary PCs of epoxy/basalt, epoxy/silica sand and epoxy/fly ash and then studied the mechanical properties such as compressive, flexural and splitting tensile strength. The mixture design method was used as an approach for design of experiment to reduce the number of tests and optimize the mechanical strength of the PC. The best weight percentages of the PC components were 25 (epoxy), 5 (fly ash), 52.5 (silica sand) and 17.5 (basalt). The compressive, flexural and splitting tensile strength of the quaternary PC were equal to 94.1, 39.0 and 11.8, which were 3.76, 11.1 and 6.5 times higher than those of ordinary Portland cement, respectively. Finally, a scanning electron microscopy test was implemented to study the microstructure of the PC.
\end{abstract}

Keywords. Polymer concrete; mechanical strength; mixture design; fly ash; silica sand; basalt.

\section{Introduction}

For each developed technology, there is always several limitations over its acceptance. Each kind of concrete, such as ordinary Portland cement (OPC) concrete, polymer concrete (PC) and geopolymer concrete, has some advantages and disadvantages. It should be noted that each kind of them has special properties for special applications. It is important to choose the best concrete for specific applications. For example, geopolymer concrete has good mechanical and thermal properties, but main limitations related to the acceptance of geopolymer in the construction field are: the high cost of alkaline solution which depends on its alkalis content; the mixing method prior to use, which takes $24 \mathrm{~h}$ to prepare the alkaline solution; some health hazards due to the high alkalinity environment possess; the brittle behaviour of geopolymer; loss of workability; quick setting time and the health and safety implications of working with strong alkali solutions. Also geopolymerization process is sensitive. This field of study has been proven inconclusive and extremely volatile [1].

Polymer concretes are composed of a resin as a binder and various types of aggregates and fillers. PCs are used in numerous applications because of their advantages like high strength and durability, fast curing time, very good adhesion properties, resistance to chemical attack, and good sound and thermal insulation properties. Various types of polymers such as polyester, epoxy, and furan resins are used in PCs [2]. Epoxy is one of the most applied thermoset polymers in PCs that has considerable mechanical properties, low curing shrinkage, strong coherence with aggregates and good durability in outdoor environments [3-6]. Also it has the ability of self-healing that can be vital in structural polymer concretes [7].

Various types of aggregates, such as siliceous foundry sand $[3,4,8,9]$, river sand $[10,11]$, pea gravel, quartz $[12,13]$, granite $[14,15]$ and basalt $[10]$, are used in PCs. Haddad and Al Kobaisi [10] used unsaturated polyester and six aggregates (basalt, spodumene, fly ash, river gravel, sand and chalk) for preparing an optimized PC. The optimum composition, with the highest flexural strength and lowest thermal expansion coefficient, was found to be basalt, sand and fly ash [10]. The increasing basalt percentages in limestone concrete mixes improved the compressive strength, indirect tensile strength, flexural strength, permeability, shear strength and modulus of rupture and reduced the thermal conductivity [16].

Fly ash is a by-product of the burning of coal in power plants and was selected as a filler because of its proven efficiency in PCs. The use of fly ash as a fine aggregate in PCs yields improved mechanical properties and chemical strength (because of its small particle size and its roundness), and the workability of the fresh PC mix reduces water absorption and results in products with an excellent surface finish.

Barbuta et al [17] studied the mechanical properties of epoxy-based PC with different types of filler (fly ash and silica fume). Experimental investigation of trinary concrete, which composed of epoxy as binder, river gravel as an aggregate and silica fume or fly ash as filler, shows that the fillers improved 
the mechanical characteristics of PC compared to that of PC without filler.

Scanning electron microscopy (SEM) studies showed that the addition of fly ash to PC results in reduced voids, and because of the regular spherical shape of the fly ash, a better packing of the aggregate-ash mixture is achieved resulting in increased strength. In addition, there is good compatibility [17-20]. High-energy ball milling is a process of synthesis for nano-materials and is used for particle size reduction. It was implemented to achieve micron and submicron sizes [21]. Tudjono et al [22] used ball milling for the preparation of nano fly ash and nano lime. The present work uses epoxy as a resin, crushed basalt and silica sand as aggregates, and micro and nano fly ash as fillers. In the present work, mechanical properties of binary PCs of epoxy/basalt, epoxy/silica sand and epoxy/fly ash are studied and the appropriate percentages of above-mentioned materials for obtaining the optimized quaternary PC that have high compressive, flexural and splitting tensile strength are provided. The optimized quaternary PC consists of epoxy as binder, ultrafine fly ash as filler, silica sand and crushed basalt as fine and coarse aggregates, respectively.

\section{Experiment}

\subsection{Materials}

The diglycidyl ether of bisphenol A resin (DGEBA), which has a low viscosity (CY 184), and the curing agent polyamine hardener (Aradur ${ }^{\circledR}$ 2965) were used as received from Huntsman (UK). The epoxy resin and hardener were processed with a maximum mix ratio of 100:15 (with low viscosity).

The fine fly ash (class F) used in this investigation was Pozzocrete $100^{\mathrm{TM}}$ from Dirk India Private Ltd, designed for application in high-performance concrete with an average particle size of $10 \mu \mathrm{m}$ and specific gravity of 2.5 . For achieving ultrafine fly ash particles, a high-energy ball milling process was performed. Figures 1 and 2 present images of scanning electron microscopy (SEM) study and particle size distribution of Pozzocrete $100^{\mathrm{TM}}$ ultrafine fly ash, respectively.

The crushed basalt aggregate used was from Kavyan Industry and Stone Company in Iran with a particle size of 1-5 mm and specific gravity of 2.8 .

The silica foundry sand used was $101^{\mathrm{TM}}$ from the Silica Sand MFG Company, from Firoozkooh mines, Iran, with a 50-200 $\mu \mathrm{m}$ particle size and specific gravity of 2.7 . The particle size distribution of silica foundry sand $101^{\mathrm{TM}}$ is shown in figure 3 .

The images of SEM studies of crushed basalt and silica sand aggregates are depicted in figures 4 and 5, respectively. The microstructures of the silica sand and basalt aggregates are not uniform in shape, and they increase the void and resin content in the PC. As observed in figure 1, the fly ash particles have a spherical shape and a smooth surface and are micron sized. This situation allows the mixture of fly ash to flow in between the silica sand and basalt particles. This condition results in a higher adhesion bonding between the polymeric matrix (epoxy) and the aggregates.

\subsection{Polymer concrete preparation method}

Before fabricating the $\mathrm{PC}$, the aggregates were dried and then mixed with the resin in an automatic mixer with a weight percentage (mentioned in the next section). The mixture was then poured into a silicone rubber mold and degassed in a vacuum oven until no air bubbles were observed on the surface. Finally, the mixture was allowed to cure for at least 1 day in the mold and for 6 days out of the mold at room temperature.

\subsection{Characterization}

All of the mechanical tests including compressive stress, three-point bending and splitting tensile tests were performed on a SANTAM Universal Testing Machine STM-150 (Iran).

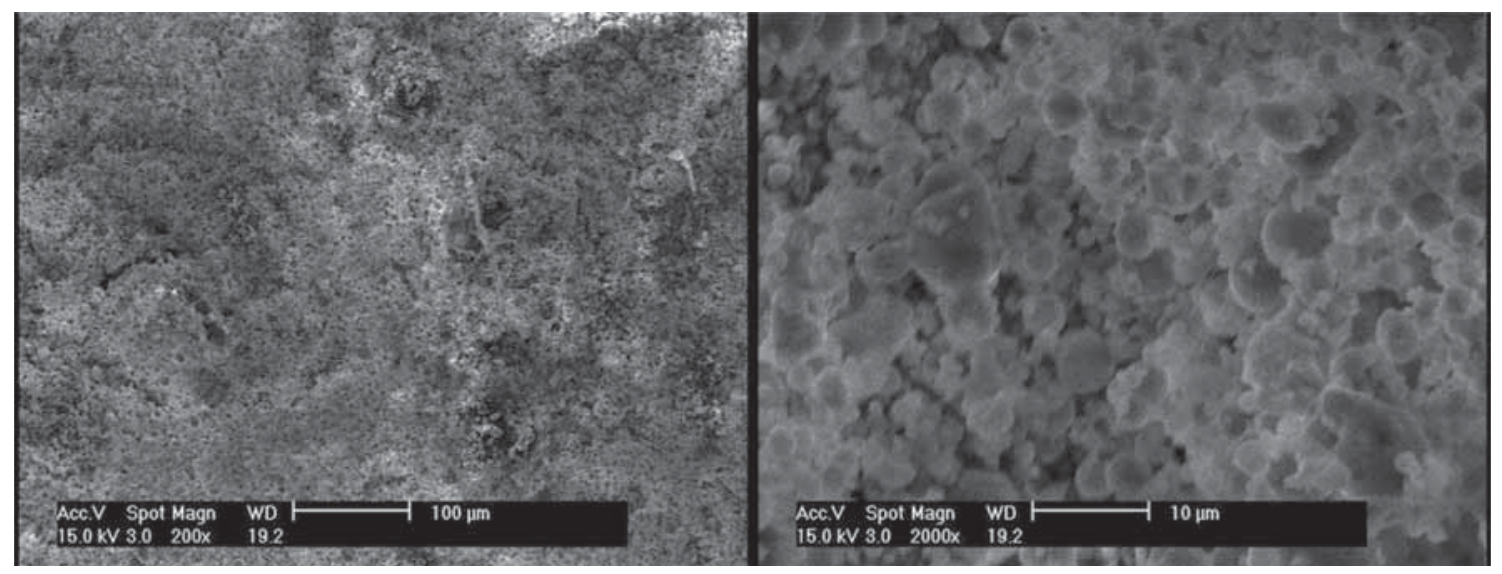

Figure 1. SEM micrographs of fly ash. 


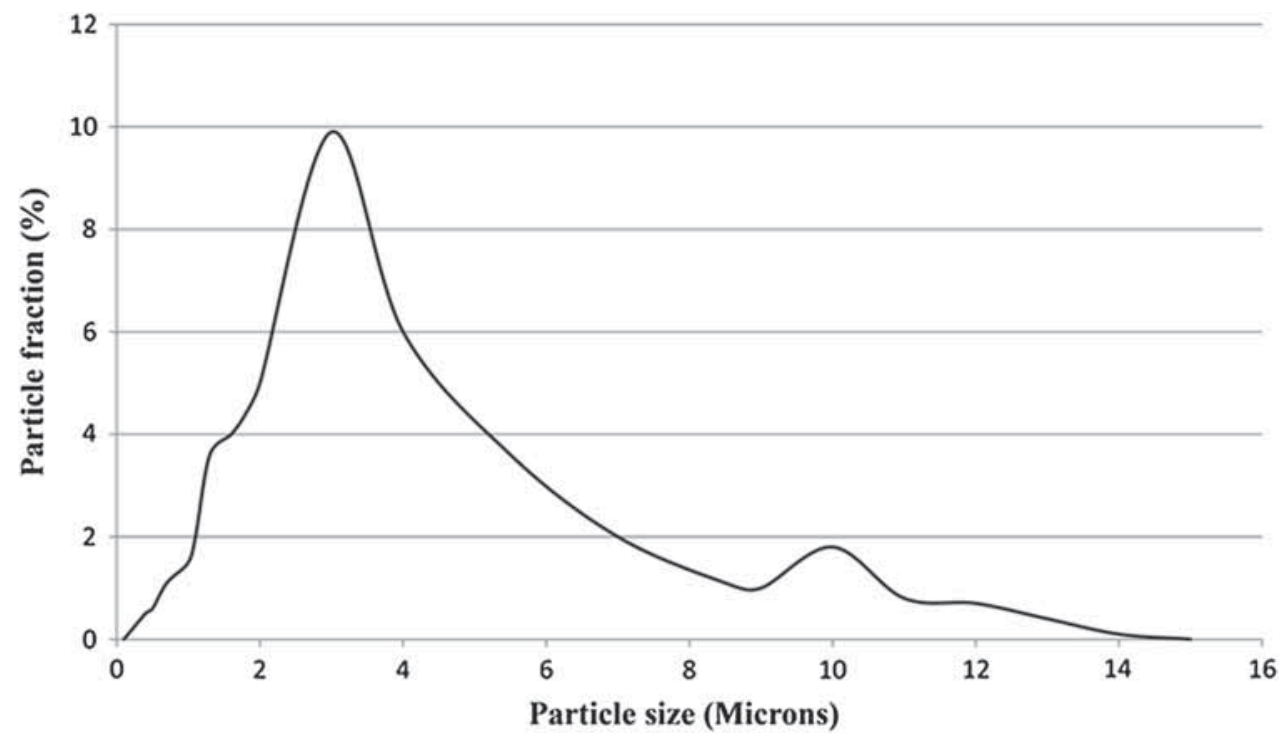

Figure 2. Particle size distribution of Pozzocrete $100^{\mathrm{TM}}$ ultrafine fly ash.

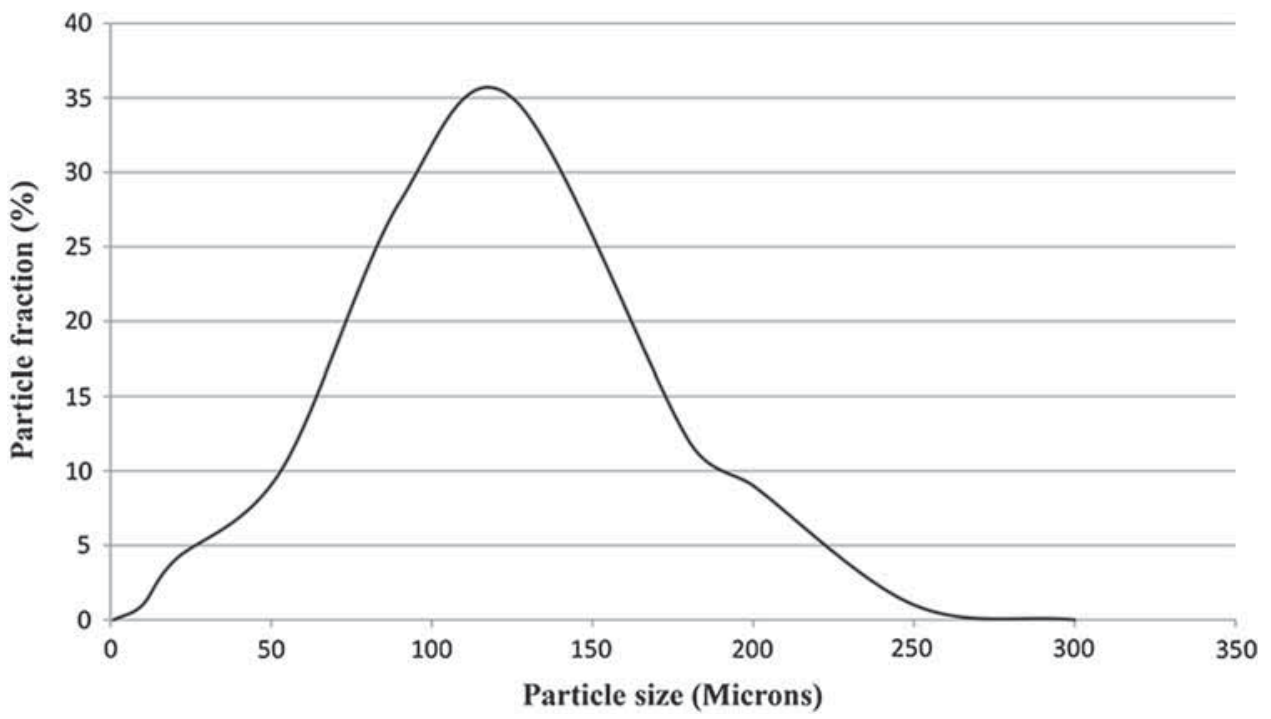

Figure 3. Particle size distribution of silica foundry sand $101^{\mathrm{TM}}$.

The compressive stress test was performed according to ASTM C39/C39M with a $1 \mathrm{~mm} \mathrm{~min}^{-1}$ crosshead velocity [23]. Three cylindrical test specimens, $50 \mathrm{~mm}$ in diameter and $100 \mathrm{~mm}$ in height, were cast to obtain the compressive strength for each composition. Figure $6 \mathrm{a}$ shows a schematic of the compressive tensile test.

The three-point bending test was performed according to ASTM C580 with a crosshead velocity of $2.7 \mathrm{~mm} \mathrm{~min}^{-1}$. A rectangular cubic shape mold with dimensions of $25 \times 25 \times$ $254 \mathrm{~mm}$ was cast for the three-point bending test [24]. A schematic and the dimensions of the samples that were used in the three-point bending test are illustrated in figure $6 \mathrm{~b}$. The flexural strength was calculated using the following equation [25]:

$$
\sigma_{\mathrm{f}}=\frac{3 P_{\mathrm{f}} L}{2 w d^{2}},
$$




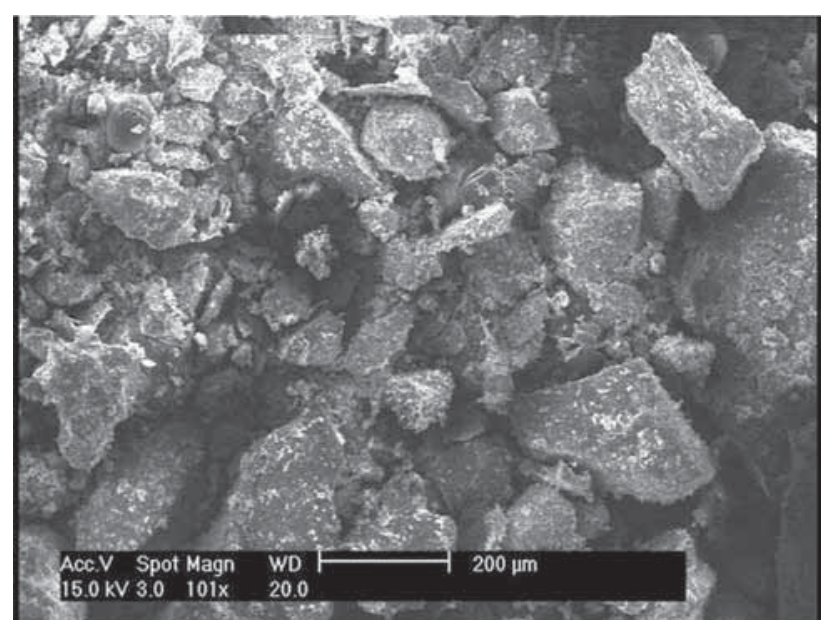

Figure 4. SEM micrographs of crushed basalt aggregate.

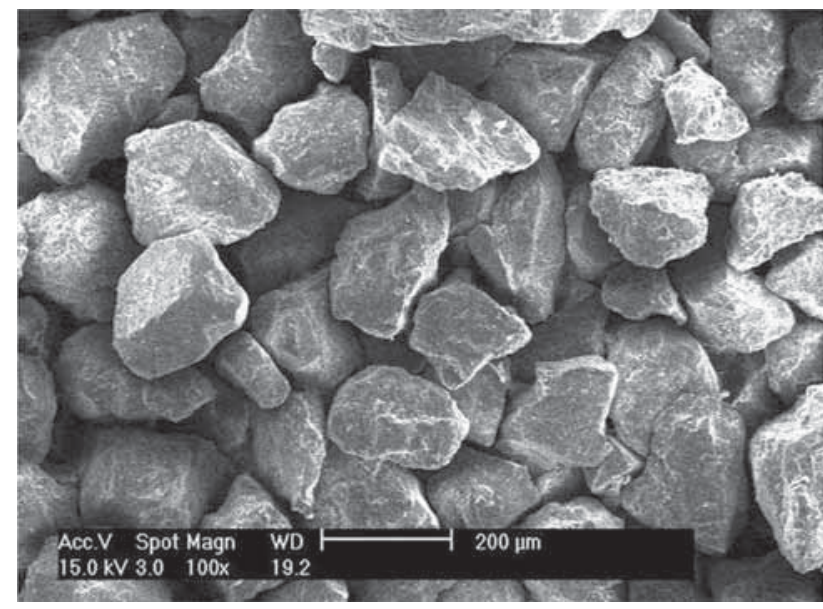

Figure 5. SEM micrographs of silica sand aggregates.

where $P_{\mathrm{f}}$ is the maximum flexural applied load indicated by the testing machine, $L$ is the span length, and $w$ and $d$ are the width and depth of the specimen, respectively. Three specimens were used to obtain the flexural strength for each composition.

The splitting tensile test is an indirect tension test for characterizing the tensile strength of concretes and is generally greater than the direct tensile strength and lower than the flexural strength (modulus of rupture) [22,23]. The splitting tensile strength of cylindrical concrete (diameter and height of 50 and $100 \mathrm{~mm}$, respectively) was performed according to ASTM C496/C496M by applying the load continuously and without shock at a constant rate of $1 \mathrm{MPa} \mathrm{min}{ }^{-1}$ until failure of the specimen [26-28]. A schematic of the samples for the splitting tensile test is shown in figure $6 \mathrm{c}$. The compression load was applied diametrically and uniformly along the length of the cylinder, and the specimen splits into two halves along the vertical plane because of the indirect tensile stress generated by Poisson's effect. The splitting tensile strength was calculated according to the following equation:

$$
\sigma_{\mathrm{t}}=\frac{2 P_{\mathrm{t}}}{\pi L D}
$$

where $P_{\mathrm{t}}$ is the maximum applied load indicated by the testing machine, and $D$ the diameter of the specimen. Three cylindrical test specimens were cast for each composition to obtain the flexural strength.

SEM was performed using a TESCAN Mira (USA) at an acceleration voltage of $15 \mathrm{kV}$ to examine the fracture surface morphology of the PCs. The fracture surface was prepared by fracturing the PC samples in liquid nitrogen. All samples were sputtered with gold prior to observation. Furthermore, the presence of different PC fillers (basalt, silica sand and fly ash) was recognized by electron dispersion X-ray (EDX) analysis.

\section{Results and discussion}

\subsection{Epoxy/basalt concrete}

To reduce the production cost of PCs, it is necessary to minimize the epoxy content in PCs. To this end, different compositions from 20 to $30 \%$ resin content were implemented for the epoxy/basalt composite in previous work [29]. Three different mechanical tests were performed to evaluate the effect of the basalt aggregate on the compressive, flexural and splitting tensile strengths of the epoxy/basalt composite. Table 1 shows the mechanical properties of the epoxy/basalt samples with different compositions. This table shows that the incorporation of $25 \mathrm{wt} \%$ epoxy resin into the basalt aggregate $(\mathrm{EP} / 75 \mathrm{Ba})$ increased the compressive, flexural and splitting tensile strength to $76.2,27.7$ and $10 \mathrm{MPa}$, corresponding to an improvement of 87,36 and $39 \%$, respectively, compared with the values for the EP/80Ba sample. Therefore, a maximum mechanical strength for the epoxy/basalt composite was achieved with $25 \mathrm{wt} . \%$ resin and $75 \mathrm{wt} . \%$ basalt content.

\subsection{Epoxy/silica sand concrete}

In this section, we investigate the effect of the silica sand content on the mechanical properties of the epoxy concrete. As shown in table 2, maximum compressive and flexural strengths of the epoxy/silica sand composite were obtained for $24 \mathrm{wt} . \%$ resin and $76 \mathrm{wt} . \%$ silica sand content $(\mathrm{EP} / 76 \mathrm{Si})$, and a maximum splitting tensile strength was achieved for $26 \mathrm{wt} . \%$ resin and $74 \mathrm{wt} . \%$ silica sand composition (EP/74Si). As shown in table 2, the incorporation of 24 wt.\% epoxy resin into the silica sand improved the compressive, flexural and splitting tensile strengths approximately 29, 50 and 51\% compared with the EP/84Si concrete, respectively. In addition, we find that the epoxy/silica sand concretes show higher mechanical properties than the epoxy/basalt concretes. An SEM investigation of the epoxy/silica sand concrete shows the homogenous distribution of aggregate particles in the matrix 
(a)

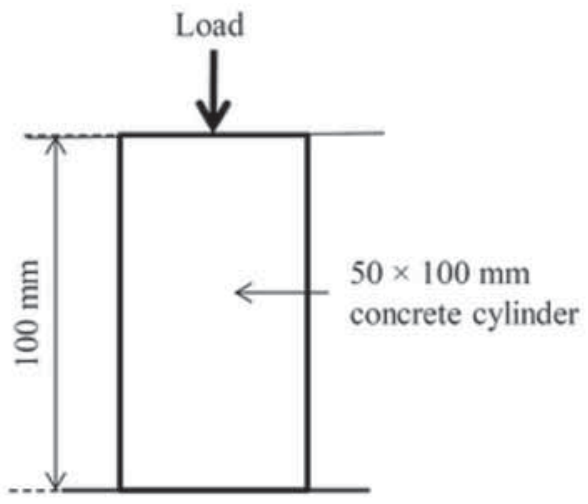

Compressive test (b)

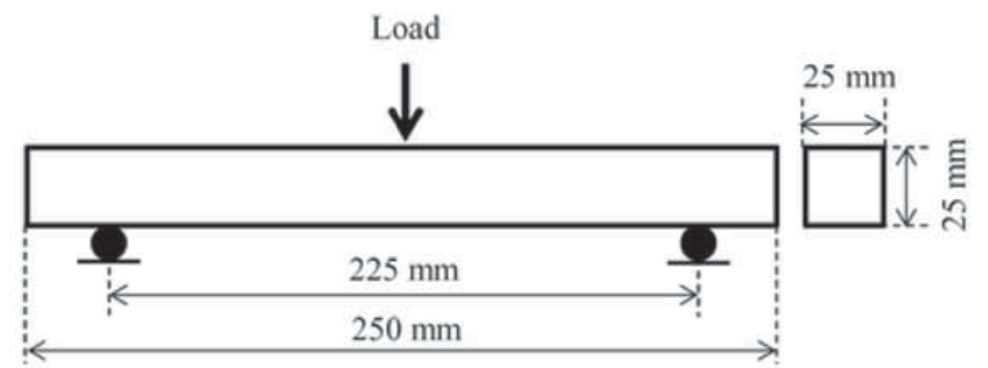

3 Point bending test

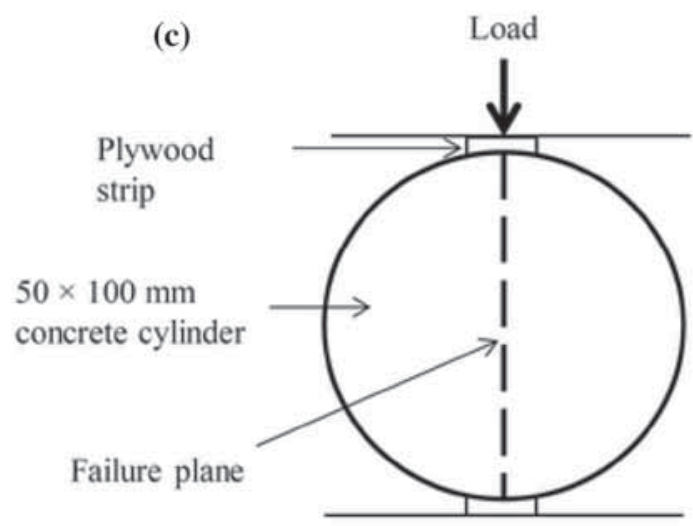

Splitting tensile test

Figure 6. Schematic and dimensions of the (a) compressive, (b) bending and (c) splitting tensile test specimens.

Table 1. Mechanical strength of the epoxy/basalt polymer concrete [29].

\begin{tabular}{lccccc}
\hline Sample code & Basalt (wt.\%) & Epoxy (wt.\%) & $\begin{array}{l}\text { Compressive } \\
\text { strength (MPa) }\end{array}$ & Flexural strength (MPa) & $\begin{array}{l}\text { Splitting tensile } \\
\text { strength (MPa) }\end{array}$ \\
\hline $\mathrm{EP}$ & 0 & 100 & 66.8 & 82.9 & 22.5 \\
$\mathrm{EP} / 80 \mathrm{Ba}$ & 80 & 20 & 40.6 & 20.3 & 7.2 \\
$\mathrm{EP} / 77.5 \mathrm{Ba}$ & 77.5 & 22.5 & 70.7 & 24.7 & 8.8 \\
$\mathrm{EP} / 75 \mathrm{Ba}$ & 75 & 25 & 76.2 & 27.7 & 10.0 \\
$\mathrm{EP} / 72.5 \mathrm{Ba}$ & 72.5 & 27.5 & 71.7 & 26.1 & 9.0 \\
$\mathrm{EP} / 70 \mathrm{Ba}$ & 70 & 30 & 68.2 & 25.2 & 8.1 \\
\hline
\end{tabular}

phase, as shown in figure 7. Furthermore, there is considerable adhesion between the silica sand particles and the epoxy binder.

\subsection{Epoxy/fly ash concrete}

Now, we consider the compressive, flexural and splitting tensile strengths of the epoxy/fly ash concretes with different amounts of fly ash filler. The above experimental results are listed in table 3. As we can see in this table, with increasing fly ash content from 12 to $18 \mathrm{wt} . \%$, the compressive strength of the epoxy/fly ash concrete increases from 75.1 to $79.3 \mathrm{MPa}$, respectively, and then decreases to $77.3 \mathrm{MPa}$ for EP/20Fly. Furthermore, the flexural and splitting tensile strengths increase to the maximum values of 51.35 and $22.94 \mathrm{MPa}$, respectively, with the addition of $16 \mathrm{wt} . \%$ fly ash to the epoxy resin. These decreases in the mechanical properties of the epoxy/fly ash concretes are due to the inherent van 
Table 2. Mechanical strength of the epoxy/silica sand polymer concrete.

\begin{tabular}{lccccc}
\hline Sample code & Silica sand (wt.\%) & Epoxy (wt.\%) & $\begin{array}{l}\text { Compressive } \\
\text { strength (MPa) }\end{array}$ & $\begin{array}{c}\text { Flexural strength (MPa) } \\
\text { strength (MPa) }\end{array}$ \\
\hline EP & 0 & 100 & 66.8 & 82.9 & 22.5 \\
EP/84Si & 84 & 16 & 60.7 & 25.1 & 8.3 \\
EP/82Si & 82 & 18 & 64.1 & 28.8 & 11.0 \\
EP/80Si & 80 & 20 & 69.7 & 30.8 & 11.3 \\
EP/78Si & 78 & 22 & 73.4 & 33.8 & 11.9 \\
EP/76Si & 76 & 24 & 78.4 & 37.8 & 12.4 \\
EP/74Si & 74 & 26 & 68.9 & 34.6 & 15.7 \\
EP/72Si & 72 & 28 & 66.8 & 33.9 & 12.3 \\
\hline
\end{tabular}

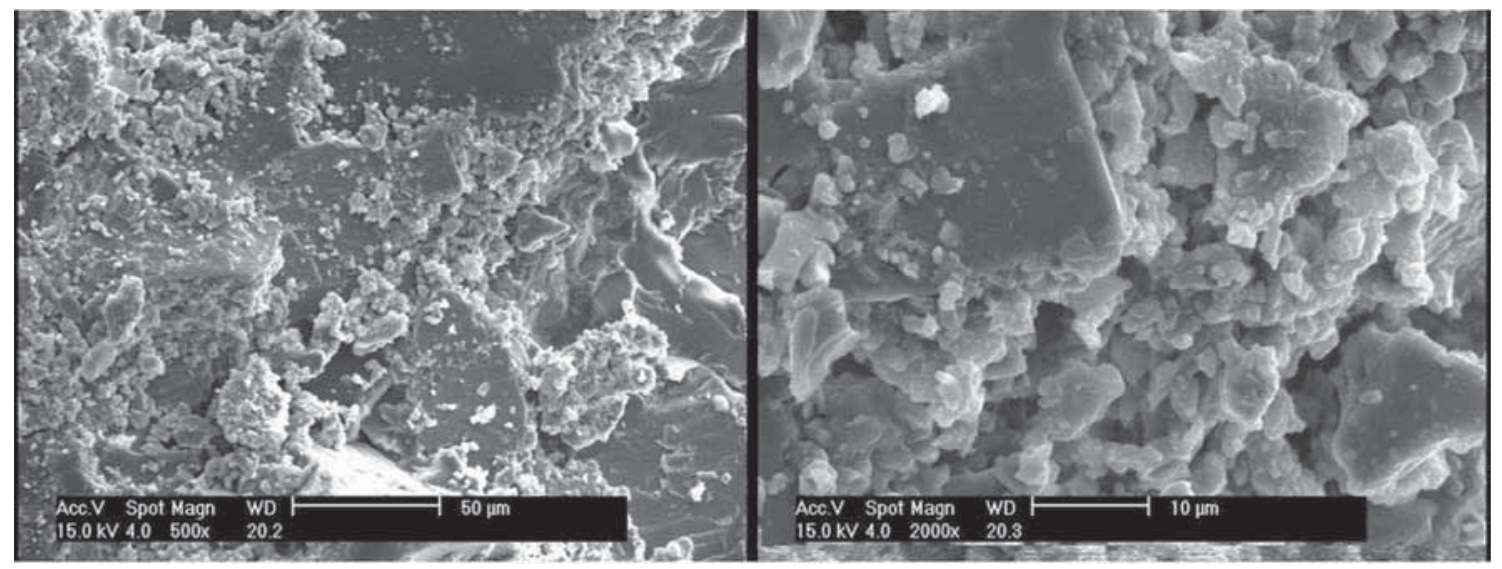

Figure 7. SEM micrographs of the fracture surface of the EP/76Si concrete sample.

Table 3. Mechanical strength of the epoxy/fly ash polymer concrete.

\begin{tabular}{lccccc}
\hline Sample code & Fly ash (wt.\%) & Epoxy (wt.\%) & $\begin{array}{l}\text { Compressive } \\
\text { strength (MPa) }\end{array}$ & Flexural strength (MPa) & $\begin{array}{l}\text { Splitting tensile } \\
\text { strength (MPa) }\end{array}$ \\
\hline EP & 0 & 100 & 66.8 & 82.9 & 22.5 \\
EP/12Fly & 12 & 88 & 75.1 & 47.1 & 19.7 \\
EP/14Fly & 14 & 86 & 76.3 & 49.9 & 20.2 \\
EP/16Fly & 16 & 84 & 78.7 & 41.4 & 22.9 \\
EP/18Fly & 18 & 82 & 79.3 & 40.2 & 22.3 \\
EP/20Fly & 20 & 80 & 77.3 & 21.8 \\
\hline
\end{tabular}

der Waals attractions between fly ash particles that readily cause the formation of more entangled agglomerates of these particles in the epoxy resin. The agglomeration of fly ash particles in the resin lead to the stress concentration and rupture start point. Thus, a good particle distribution improves the mechanical strength. According to the above results, more than 16 wt.\% of fly ash caused a decrease of the workability and strength of the PC. Moreover, the SEM study of the epoxy/fly ash concrete confirms the homogenous dispersion of fly ash particles in the polymer matrix with good adhesion bonding between the polymer phase and the fly ash filler (figure 8).

\subsection{Optimization of quaternary PC using the mixture design approach}

To find the optimum weight percentages of epoxy resin, basalt, silica sand and fly ash in the quaternary PC, first, two-phase concretes (epoxy/basalt, epoxy/silica sand and epoxy/fly ash) were prepared and tested, as shown in the previous sections. After analysing the mechanical properties, the quaternary PCs were optimally designed by using resin, basalt, silica sand and fly ash to have the highest compressive, flexural and splitting tensile strengths, simultaneously. From tables 1 and 2, the optimum weight percentage of resin in the PC 

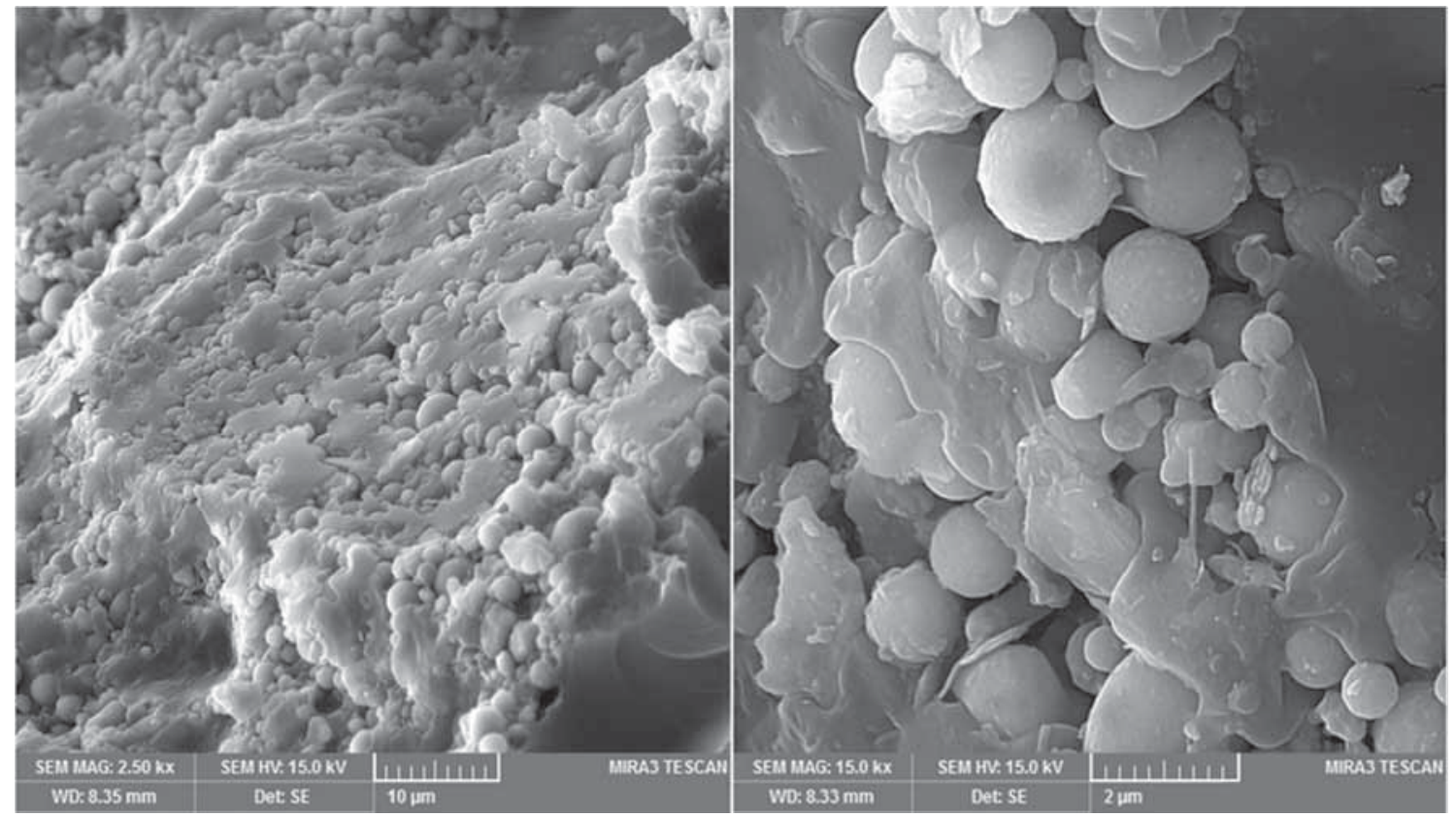

Figure 8. SEM micrographs of the fracture surface of the EP/16Fas concrete sample.

is nearly $25 \mathrm{wt} . \%$, and from table 3 , the best mechanical properties are obtained when the fly ash to resin ratio is $16-84$ (about 0.2). Therefore, the resin and fly ash contents are 25 and $5 \mathrm{wt} . \%$, respectively, and are constants, while the silica sand and crushed basalt contents are variables. By considering these two variables, the PC is optimally designed to have the highest compressive, flexural and splitting tensile strengths, simultaneously. To this end, the mixture design method as an approach for the design of experiments (DOE) is used to reduce the number of tests. DOE is a structured technique for studying any situation that involves a response that varies as a function of one or more independent variables and is specifically designed to address complex problems where more than one variable may affect a response and two or more variables may interact with each other [30]. In this study, Minitab software version 17.0.1 was used for analysing and optimizing the results. At this stage, the upper and lower bounds of each variable were selected. Table 4 represents the mixture design components and their bounds. The resin and fly ash contents selected were 25 and $5 \mathrm{wt} \%$, respectively. Therefore, the summation of the crushed basalt and silica sand weight percentage is equal to $70 \mathrm{wt} . \%$. For creating the mixture design, a simplex centroid type with two components and three runs was selected, and the type of design was a full factorial with a fraction number of 1 . Table 5 shows the standard 5 runs that resulted in the mixture design method. For the preparation of the PC, silica sand and crushed basalt aggregates with the expected weight percent were added and mixed with the epoxy/fly ash blend. After fabrication of the PC specimens, compressive, flexural and splitting tensile tests were performed, and the strength values are listed in table 6 . According
Table 4. Upper and lower bounds of each variable.

\begin{tabular}{lccc}
\hline Component & Name & $\begin{array}{l}\text { Lower } \\
(\text { wt.\%) }\end{array}$ & $\begin{array}{l}\text { Upper bond } \\
\text { (wt.\%) }\end{array}$ \\
\hline A & Silica sand & 0 & 70 \\
B & Basalt & 0 & 70 \\
\hline
\end{tabular}

to the obtained results from the mixture design approach, Run-2 shows the highest compressive and flexural strength with values of 94.1 and $39.0 \mathrm{MPa}$, respectively. Furthermore, the splitting tensile strength with this PC composition is equal to $11.8 \mathrm{MPa}$. We also find that Run-4 has the highest splitting tensile strength (12.4 MPa), but its compressive and flexural strengths are lower than those of Run-2. Therefore, Run-2 with 25 wt. $\%$ resin, 5 wt.\% fly ash, 52.5 wt. $\%$ silica sand and 17.5 wt.\% crushed basalt was selected as an optimized PC. Stress-strain diagrams of the five different runs with various contents are shown in figure 9. The results show that the optimized quaternary PC (Run-2) has higher compressive, flexural and splitting tensile strengths than do the epoxy/silica sand concretes. We also found that the compressive strength of the Run-2 sample is more than that of the epoxy/fly ash sample.

An SEM investigation of the Run-2 specimen with $25 \mathrm{wt} . \%$ resin, 5 wt.\% fly ash, 52.5 wt.\% silica sand and 17.5 wt.\% crushed basalt composition is shown in figure 10. This micrograph presents a homogeneous dispersion of aggregates in the epoxy resin. Furthermore, EDX analysis indicates that the points A and B in the SEM micrograph can be attributed to 
Table 5. Standard 5 runs resulted in the mixture design method.

\begin{tabular}{lcccc}
\hline Test runs & Epoxy content (wt.\%) & Fly ash content (wt.\%) & Silica sand content (wt.\%) & Basalt content (wt.\%) \\
\hline Run-1 & 25 & 5 & 70 & 0 \\
Run-2 & 25 & 5 & 52.5 & 17.5 \\
Run-3 & 25 & 5 & 35 & 35 \\
Run-4 & 25 & 5 & 17.5 & 52.5 \\
Run-5 & 25 & 5 & 0 & 70 \\
\hline
\end{tabular}

Table 6. Mechanical properties of quaternary polymer concrete at 5 runs.

\begin{tabular}{lccc}
\hline Test runs & Compressive strength (MPa) & Flexural strength (MPa) & Splitting tensile strength (MPa) \\
\hline Run-1 & 82.2 & 33.2 & 10.4 \\
Run-2 & 94.1 & 39.0 & 11.8 \\
Run-3 & 92.9 & 35.7 & 11.6 \\
Run-4 & 93.6 & 30.6 & 12.4 \\
Run-5 & 78.5 & 28.0 & 8.5 \\
\hline
\end{tabular}

(a)

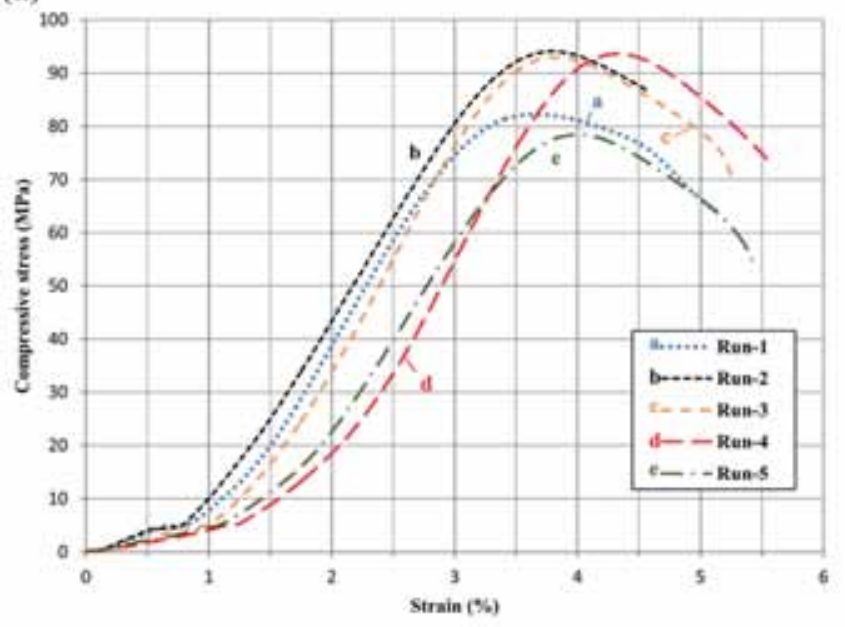

(b)

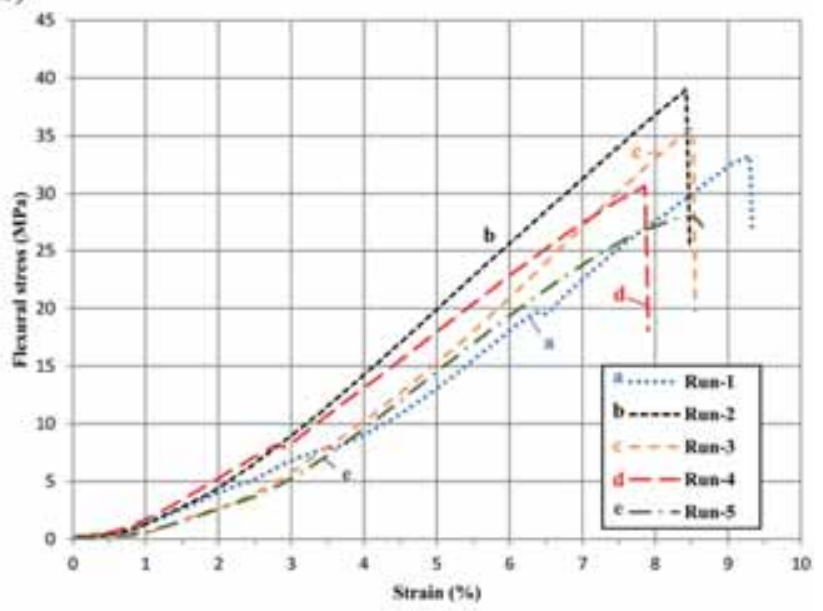

(c)

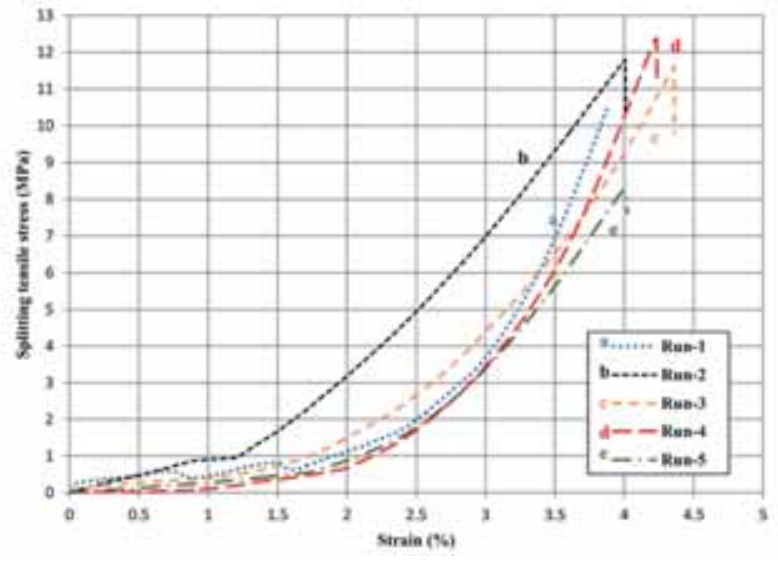

Figure 9. (a) Compression and (b) flexural and splitting tensile stress vs. strain diagrams for five different runs. 

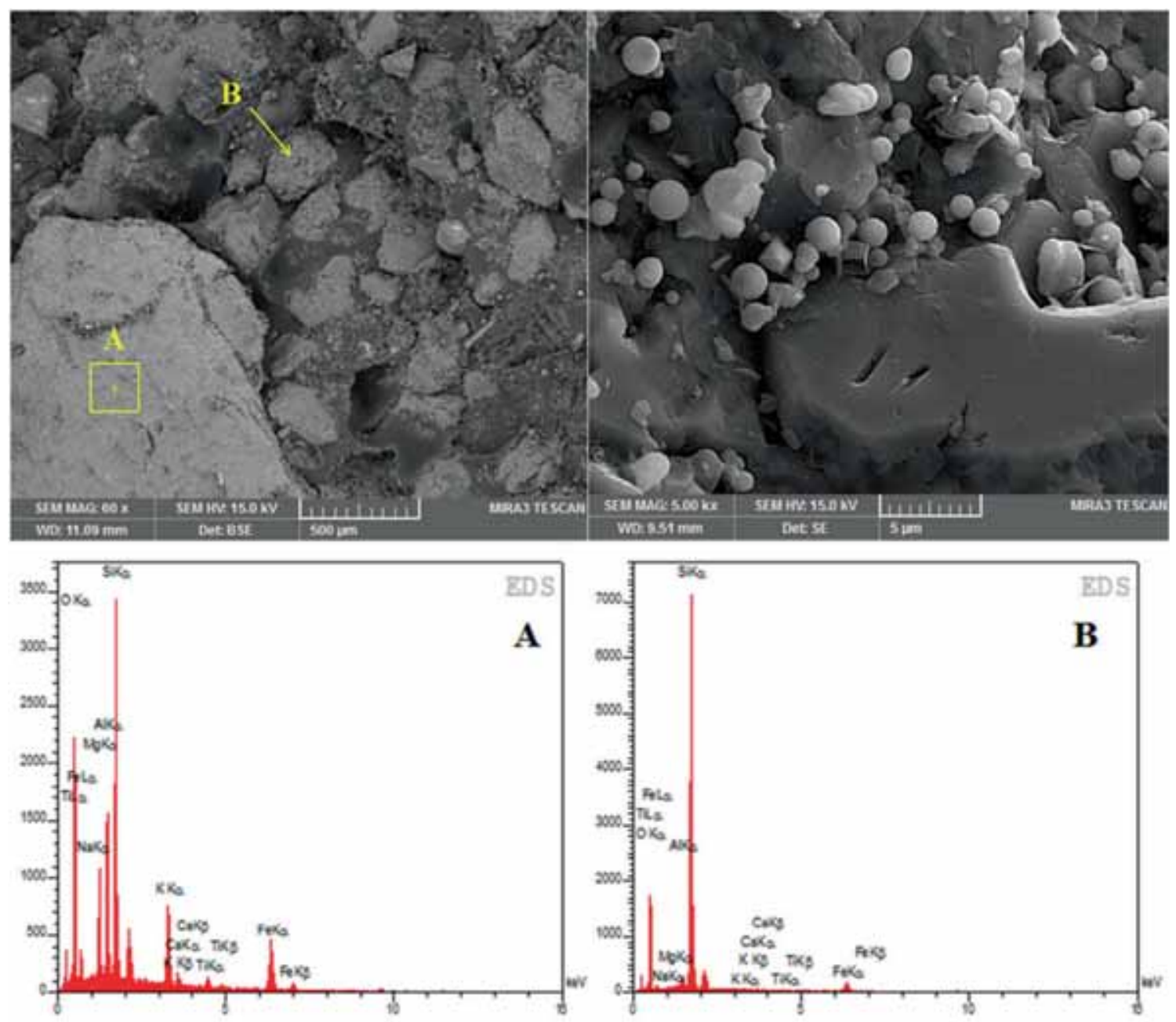

Figure 10. SEM micrographs of the fracture surface and EDX analysis for the Run-2 specimen at different resolutions.

the basalt and silica sand, respectively. We also see that fly ash particles fill the space between the silica sand and basalt aggregates with epoxy resin, decreasing the voids, and lead to an enhancement of the mechanical strength of the PC. Therefore, this composition can decrease content of the resin in the $\mathrm{PC}$ and reduce the price of concrete.

Figure 11 represents a comparative study of the compressive, flexural and splitting tensile strengths of the resultant optimum PC of this investigation with an OPC concrete at day 28 of curing [31]. As observed, the compressive, flexural and splitting tensile strengths of quaternary $\mathrm{PC}$ are $3.76,11.1$ and 6.5 times higher than those of the OPC concrete, respectively. It is necessary to note that the quaternary PC has a very high compressive strength immediately after a short time of curing (even after 1 day of curing).

\section{Conclusions}

In this work, we first investigated the effect of each basalt, silica sand and fly ash on the mechanical properties of epoxy PCs. Based on our results, the orders of compressive, flexural and splitting tensile strength values in PCs are as follows: epoxy/fly ash $>$ epoxy/silica sand $>$ epoxy/basalt. Furthermore, these results represent remarkable properties compared with an OPC. Finally, to increase the mechanical properties and to decrease the content of the resin in the PC, we used basalt, silica sand and fly ash to create a quaternary PC. Therefore, the mixture design method was used as an approach for DOEs to reduce the number of tests and find the optimum weight percent of each aggregate. Our results show that the quaternary PC with $25 \mathrm{wt} . \%$ resin, $5 \mathrm{wt} . \%$ fly ash, 52.5 wt. \% silica sand and 17.5 wt.\% crushed basalt can be selected as an optimized PC. The compressive, flexural and splitting tensile strengths of this quaternary PC are equal to 94.1, 39.0 and $11.8 \mathrm{MPa}$, which is $3.76,11.1$ and 6.5 times higher than OPC, respectively. The SEM investigation on the fracture surface of the optimum quaternary PC presents a homogeneous dispersion of the aggregates in the epoxy resin.

Ultrafine fly ash particles (with an average dimension of $10 \mu \mathrm{m}$ ) that have spherical shapes fill the spaces between silica sand aggregates (with an average dimension of $150 \mu \mathrm{m}$ ) 


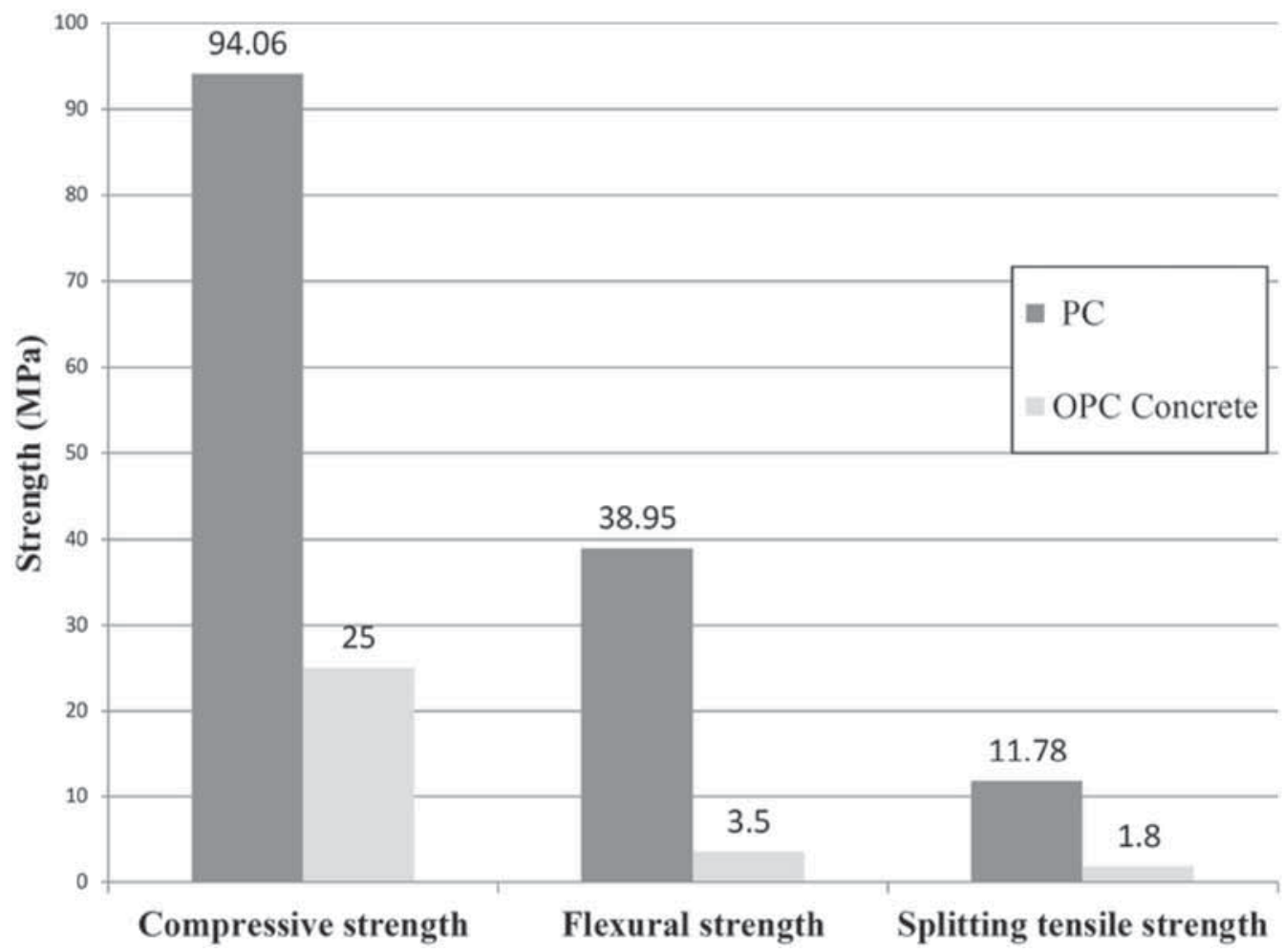

Figure 11. Comparative study of the mechanical properties of quaternary PC and OPC concrete.

and reduce the voids. Also combination of fly ash and silica sand particles fill the voids of crushed basalt aggregates (with an average dimension of $3 \mathrm{~mm}$ ). By using filler and aggregates with different shape and size, the voids, stress concentration area of concrete were decreased. As resulted in the presented paper, the quaternary PC has better mechanical properties than each of binary (two phase) systems. So implementing three kinds of filler and aggregates in the PC causes better package of concrete and increase the mechanical properties.

On the other side, each of filler and aggregates used in quaternary PC have different physical and mechanical properties. As resulted in experimental investigations of binary PCs, each of epoxy/fly ash, epoxy/basalt and epoxy/silica sand systems have specific mechanical properties. For example, epoxy/fly ash system has more flexural strength than the others. So implementing the fly ash increases the flexural strength of PC. Therefore, by combination of fillers and aggregates (in quaternary system), we enhanced the mechanical properties of the PC.

The presented PC can be used as structural concretes in aquatic and corrosive environments, bridge deck overlay, construction of precast members like pipes, acid tanks, manholes and drains.

The presented PC is easy to produce for large-scale construction projects, because its materials do not give any annoying chemical reaction together and the preparation method is easy. All of the aggregates and filler that are used in the presented PC have low cast. The pot life of implemented epoxy resin after adding hardener is about 50 min for low volume applications and about $20 \mathrm{~min}$ for high volume applications in $25^{\circ} \mathrm{C}$.

\section{References}

[1] Aleem M I A and Arumairaj P D 2012 Int. J. Eng. Sci. Emerg. Technol. 1118

[2] Bedi R, Chandra R and Singh S P 2013 J. Compos. 20131

[3] Reis J M and Ferreira A J 2004 Constr. Build. Mater. 18523

[4] Elalaoui O, Ghorbel E, Mignot V and Ben Ouezdou M 2012 Constr. Build. Mater. 27415

[5] Shokrieh M M, Kefayati A R and Chitsazzadeh M 2012 Mater. Des. 40443

[6] Harja M and Arbut M B 2008 Bulletin Polytechnic Institute of Jassy-Constr. Archit Section 1

[7] Ghorbanzadeh Ahangari M and Fereidoon A 2015 Mater. Chem. Phys. 151112

[8] Reis J M L, Moreira D C, Nunes L C S and Sphaier L A 2011 Mater. Sci. Eng. A $\mathbf{5 2 8} 6085$

[9] Ferreira A J M, Marques A T, Ribeiro M C S and Nóvoa P R 2004 Cem. Concr. Compos. 26803

[10] Haddad H and Al Kobaisi M 2012 Compos. Part B Eng. 43 3061

[11] Rebeiz K S 1995 Cem. Concr. Compos. 17119

[12] Mani P, Gupta A K and Krishnamoorthy S 1987 Int. J. Adhes. Adhes. 7157

[13] Yu R, Spiesz P and Brouwers H J H 2014 Constr. Build. Mater. 65140 
[14] Agavriloaie L, Oprea S, Barbuta M and Luca F 2012 Constr. Build. Mater. 37190

[15] Wahab A, Kumar B D, Bhaskar M and Kumar S V 2013 Int. J. Sci. Eng. Res. 45

[16] Al-Baijat H M 2008 Jordan J. Civil Eng. 263

[17] Barbuta M, Harja M and Baran I 2010 J. Mater. Civ. Eng. 22 696

[18] Rivera F, Martínez P, Castro J and López M 2015 Cem. Concr. Compos. 63104

[19] Gorninski J P, Dal Molin D C and Kazmierczak C S 2004 Cem. Concr. Res. 342091

[20] Lokuge W and Aravinthan T 2013 Mater. Des. 51175

[21] Prasad Yadav T, Manohar Yadav R and Pratap Singh D 2012 Nanosci. Nanotechnol. 222

[22] Tudjono S, Purwanto and Apsari K T 2014 Procedia Eng. 95 426
[23] ASTM S.T. Method 2014 C 39/C 39M ASTM Int. 14

[24] ASTM S.T. Method 2011 C 580 ASTM Int. 21

[25] Ary Subagia I D G and Kim Y 2013 J. Mech. Sci. Technol. 27 987

[26] Gerges N N, Issa C A and Fawaz S 2015 Case Stud. Constr. Mater. 383

[27] Ibrahim M H W, Hamzah A F, Jamaluddin N, Ramadhansyah P J and Fadzil A M 2015 Procedia-Soc. Behav. Sci. 195 2280

[28] ASTM S.T. Method 1996 C 496/C 496M ASTM Int. 41

[29] Hassani Niaki M, Fereidoon A and Ghorbanzadeh Ahangari M 2017 Struct. Concrete 20171

[30] Arnold S F 2012 Design of Experiments with MINITAB Am. Stat. 60205

[31] Jamshidi M and Pourkhorshidi A R 2010 Asian J. Civil Eng. 11421 